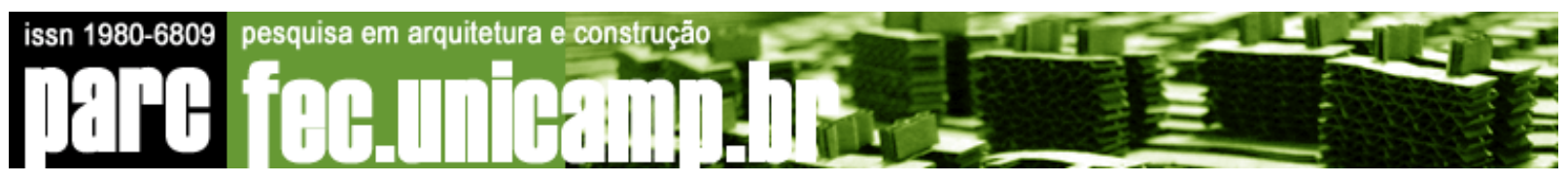

\title{
A condição do estranhamento arquitetônico na Contemporaneidade
}

\author{
The architectural uncanny condition in contemporaneity
}

\section{DIOGO RIBEIRO CARVALHO}

Estudante de graduação em Arquitetura e Urbanismo da Escola de Arquitetura da Universidade Federal de Minas Gerais, membro do Programa de Educação Tutorial PET ARQUITETURA UFMG (PET . DEPEM . SESu . MEC), vinculado ao Departamento de Análise Crítica e Histórica da Arquitetura e do Urbanismo, e tutoriado pela Professora Doutora Celina Borges Lemos.

rcdiogo5@yahoo.com.br

\section{Resumo}

Este trabalho, orientado pela Professora Doutora Celina Borges Lemos, trata doestudo acerca da categoria do sublime na arquitetura contemporânea, a partir da discussão do retorno da esfera humana no discurso pós-moderno; da idéia de unheimlich (inquietante estranheza) de Freud; da fragmentação do corpo humano e da arquitetura (Eisenman, Coop Himmelblau, Tshumi); de forma a compreender a questão da imagem do novo e velho no espaço e tempo presentes.

Tal pesquisa se justifica na medida em que a investigação crítica acerca da produção arquitetônica se faz necessária para a sua própria criação. O (re)pensar o contexto recente da atividade projetual, pelo entendimento do homem sobre seu mundo e das questões inerentes à cidade da pós-modernidade, é fundamental para aprimorar a sensibilidade do próprio pesquisador a fim de disseminar esse conhecimento no campo profissional e acadêmico. Espera-se a compreensão e análise do que poderia ser denominado como corpo .estranho. na arquitetura contemporânea e sua relação com o corpo antigo da cidade. Ao perceber o espaço urbano como acontecimento, como uma sucessão de eventos, pretende-se entender a sua dinamicidade e complexidade pela sobreposição de estruturas morfológicas, que se mostram como representativas do modo de viver do homem atual.

Palavras-chave: pós-modernismo, sublime, uncanny, desconstrução.

\section{Abstract}

This paper, assisted by Professor Dr. Celina Borges Lemos, is about the study of the sublime category in contemporary architecture, starting from the discussion of the return of the human into the postmodern discourse; the Freud.s idea of unheimlich; the fragmentation of human body and architecture 


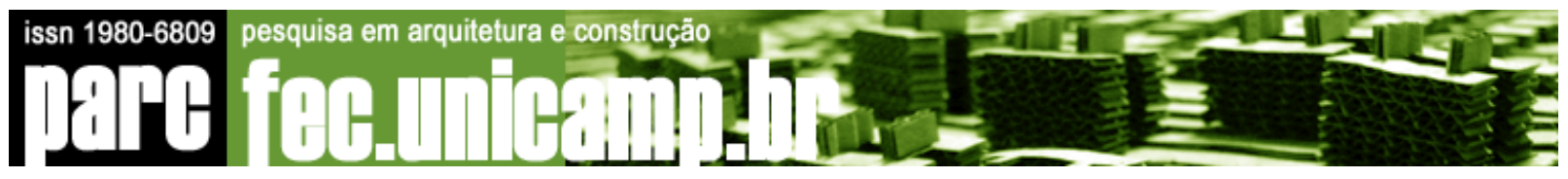

(Eisenman, Coop Himmelblau, Tshumi); so that one can understand the issue of new and old in present space and time. Such research justify itself for the critical investigation concerning the architectural production is necessary to its own creation. To (re)think the recent context of designing activity, by the understanding of man and his world and the post-modern city issues, is essential to develop the sensibility of this researcher to disseminate knowledge in professional and academic field. The comprehension and analysis of what could be defined as a strange body into contemporary architecture and its relation to the old body of the city is expected. Considering urban space as interaction of events, it is aimed the recognition of its dynamics and complexities by the superposition of morphological structures, representative of present-day man.s way of life.

Keywords: post-modernism, sublime, uncanny, deconstruction.

\section{A condição do estranhamento arquitetônico na Contemporaneidade}

\section{CONDIÇÕES PÓS-MODERNAS}

O surgimento da pós-modernidade não aconteceu de imediato, nem irrompeu contra a condição modernista capitalista por mera vontade de mudança. As transformações já vinham ocorrendo no modo de pensar e agir das pessoas, na economia, na arquitetura e nas artes em geral, da mesma forma que os devidos questionamentos de diversos antropólogos, sociólogos e urbanistas começaram a aparecer após a Segunda Guerra Mundial.

O aspecto transfigurador dos pensamentos e das atitudes do indivíduo sobre o mundo em que vive, por meio das conjunturas que ele próprio cria, é inerente ao tempo e à história, de modo que o ato de mudar se torna natural. O psicanalista suíço Carl Gustav Jung afirma que em meio à perda das tradições morais e espirituais, o indivíduo da década de 1950 sofria de uma enorme sensação de vazio e tédio, como se estivesse à espera de algo que nunca acontece. E de certa forma, estava. Onde foi parar a emancipação humana universal pela mobilização das forças da tecnologia, da ciência e da razão? E o homem modelo? Que modelo? A dinâmica capitalista os engoliu pela rapidez e efemeridade de sua estrutura, causando um processo de alienação e desenraizamento deste homem. JUNG (1964:212) entende também que o racionalismo intensificado destruiu a capacidade de pessoas para reagir a símbolos e idéias, deixando-as a mercê do .submundo. psíquico. Mudar, pois, se mostrava natural 


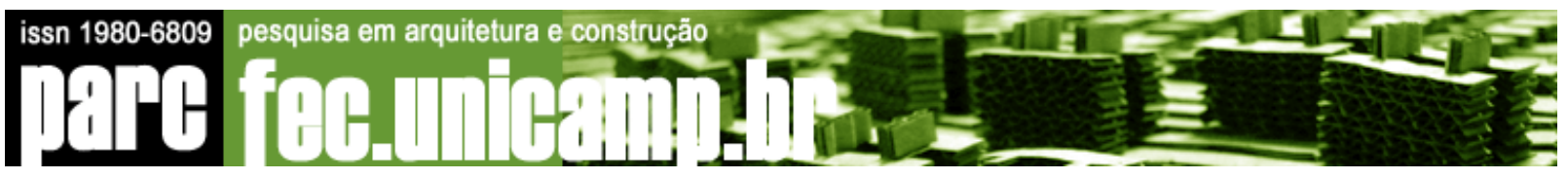

frente a insustentabilidade do processo de simplificação e padronização, que não raro representava empobrecimento cultural.

Charles Jencks (1985:235) mostra, ao avaliar o período pós-guerra, a necessidade de um modelo, um padrão, um lugar comum onde a sociedade pudesse se apoiar, que não na tábula rasa modernista. Tomemos por exemplo as respostas habituais da maior parte das políticas habitacionais desse período que ilustram esse estado:

A vida do homem urbano estava a tornar-se mais anônima e móvel;

ou, em termos arquitetônicos, havia um movimento inexorável de sistemas simbolicamente ricos para sistemas empobrecidos, de papéis culturais para papéis funcionais, ou, muito simplesmente, de lugar para espaço (JENCKS, 1985:283).

O que pode ser considerado como movimento pós-moderno em arquitetura e urbanismo ocorreu de maneira indissociável a uma mudança na .estrutura do sentimento.. David Harvey (2003:49) lembra que o romance pós-moderno, por exemplo, traz as idéias de coexistência, colisão e interpenetração de realidades radicalmente distintas, que levam à dissolução da fronteira entre ficção e ficção científica. O autor cita Foucault, que percebe que os desejos, pensamentos e ações passam gradativamente, em função do sistema capitalista do consumo de massa, a se desenvolverem .através da proliferação, da justaposição e da disjunção., e há a preferência pelo que é positivo e múltiplo, pela diferença à uniformidade, pelos fluxos às unidades e pelos arranjos aos sistemas. Existe, pois, uma total aceitação do efêmero, do fragmentário, do descontínuo e do caótico.

Da mesma forma que parece haver uma indeterminação entre o real e sua simulação, há a dissipação dos limites do tempo e do espaço, advinda da simultaneidade de olhares globais e locais, de um novo internacionalismo e fortes diferenciações internas em cidades e sociedades baseadas no lugar, na função e no interesse social. Associadas a isso, o surgimento de novas tecnologias, em especial os modelos computacionais, permite a produção em massa flexível de produtos .quase personalizados., diferindo da ordinária produção e repetição serializada. Destarte, em vez de perseguir planos grandiosos tomando como base um zoneamento funcional, adotam-se estratégias pluralistas e orgânicas para a abordagem do desenvolvimento urbano enquanto uma colagem de espaços e misturas altamente diferenciadas. Venturi já dizia da importância da justaposição de contrastes e do que 
chamou de superadjacências; a multiplicidade de níveis de significado é fundamental quando se trata da conjuntura urbana, pela quantidade de contextos distintos em interlocução. A sensibilidade de perceber tais contextos e suas interlocuções parte do princípio de ver as coisas familiares de um modo não familiar e de pontos de vista inesperados. Dessa forma, o ambíguo seria a discrepância entre fato físico e efeito psíquico; a justaposição daquilo que é e do que parece ser e suas implicações no ser que vivencia o espaço é justamente o que procura o arquiteto. O resultado dessa (con)fusão é a imprecisão de significado como a principal virtude poética, é a supremacia da riqueza de significado sobre a clareza de significado. A individualização da percepção e a conseqüente multiplicidade de visões de uma mesma coisa sugere a limitação das ordens compostas e criadas pelo homem.

Charles Jencks (1985:362) entende que o fato de a obra dita multivalente estimular a mente de um indivíduo para que vá além de suas abstrações familiares e tente novas interpretações é sempre uma justificativa para a arquitetura criativa. $\mathrm{O}$ autor, quando fez esta afirmativa, considerou a arquitetura modernista como impositiva, no sentido de estabelecer uma significação única para a obra. No entanto, pensar que discurso arquitetônico é limitante de significado é extremamente equivocado. Norberg-Schulz já dizia em 1964, em seu livro Intentions in Architecture, que toda a forma, incluindo a forma urbana, é apercebida culturalmente; ou seja, através de esquemas apreendidos a partir de uma cultura. É interessante pensar em multiplicidade de significações, uma vez que o significado é resultado da interação das intenções culturais presentes na mente de um indivíduo com o objeto de percepção, porém, não cabe a ninguém julgar quantos significados uma obra possui ou pode produzir.

Quando um novo corpo é inserido em um tempo e lugar particulares, são estabelecidos, na mente de um sujeito, elos entre sentidos passados e presentes, de modo que o objeto e as intenções culturais entram em um processo metamórfico de hipóteses e correções. Essa .metamorfose. da paisagem urbana e, por conseguinte, do imaginário urbano é decorrente da inerente relação de coexistência entre o novo e o velho na cidade contemporânea. Formalmente e culturalmente, a imagem da cidade compreende tanto as idiossincrasias e tradições locais como as relações e fenômenos de escala global. A sobreposição de estruturas ao longo da história é natural, sejam quais forem: de morfologia urbana, formas arquitetônicas, relações sociais, políticas, econômicas, topografia, simbologia, etc. O surgimento de sempre um mais novo é 


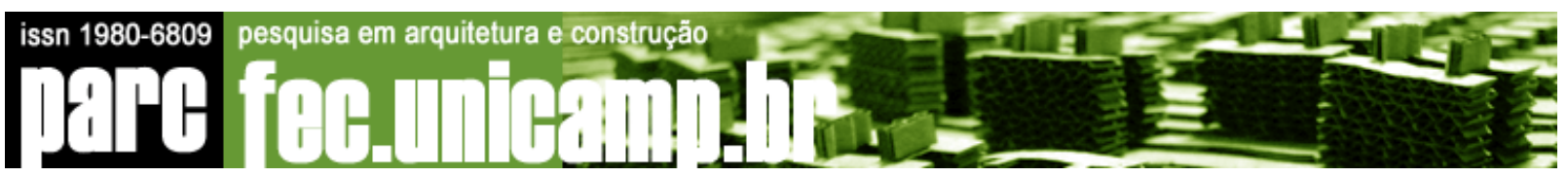

fundamental para a inovação, para a transformação; por isso, sempre existirá em algum momento a transgressão junto à tradição.

Nenhum lugar possui uma estrutura rígida e fixa, que permaneça em um mesmo estado eternamente. Tanto pode o próprio lugar sofrer alterações em um determinado intervalo de tempo, como pode o olhar de quem o vive ser mudado em função de qualquer fator influente em seu entendimento daquele espaço e dos significados a ele atribuídos. No entanto, perceber um espaço enquanto um processo, uma constante transformação, não pressupõe necessariamente a perda ou modificação do espírito do lugar, ou o seu genius loci. Essa categoria denota exatamente o que algo é, ou, fazendo uso de uma expressão Kahniana, .o que uma coisa quer ser.. Existe uma certa ambigüidade quando falamos em transformação e permanência, que nos coloca na questão de compatibilização de ambas em um determinando sítio. A condição de dinamicidade somente se relaciona com a de estaticidade pela capacidade de qualquer lugar de receber diferentes conteúdos em seu continente.

Geralmente, o caráter de um conjunto de edifícios de um determinado sítio é condensado em motivos estéticos característicos, como tipos particulares de janelas, portas e coberturas. A identidade de um local é tanto dada pelo convencional quanto pelo insólito, o que nos faz retomar o ponto da inserção do novo em contextos já consolidados culturalmente. Quando um elemento estranho é implantado em uma paisagem familiar, a estrutura espacial e morfológica logicamente se modifica, no entanto, perguntamo-nos, seu caráter fundamental permanece o mesmo? Abordagens que parecem ser relevantes na interpretação dos edifícios e projetos contemporâneos, ensejadas pelo ressurgimento do interesse pelo .estranho., têm sido importantes na discussão fenomenológica da arquitetura, entendendo esse termo enquanto metáfora de uma condição moderna fundamentalmente impossível de ser vivida. A discussão da categoria do sublime na arquitetura contemporânea é o próximo passo para o entendimento de como se deu a formação da condição pós-moderna.

\section{$O$.ESTRANHAMENTE FAMILIAR.: A CATEGORIA DO SUBLIME}

O paradigma fenomenológico definido na pós-modernidade, que aponta para uma abertura da visão para uma outra realidade de percepção, como o reino dos sonhos, da imaginação e de vivências já esquecidas, introduz uma questão fundamental no campo da estética: o efeito que uma obra de arte ou de arquitetura produz nas pessoas, seus fruidores. No caso específico do sublime, a principal categoria estética 
surgida neste contexto, a experiência se torna visceral. O sublime contém dentro de si uma condição que o Belo convencional reprime, que seria aquilo que é incerto, indizível, não natural, não presente, não-físico, o grotesco (EISENMAN, 2006:614). Anthony Vidler entende esse lado obscuro por .uncanny., .unhomely., algo .estranhamente familiar.. O uncanny coloca em primeiro plano o corpo e o sujeito em relação à experiência vivida da arquitetura e da cidade, por isso o tema permite examinar as origens, o significado e o impacto da fragmentação para o indivíduo, um ponto importante tanto para a arquitetura pós-moderna historicista, como para a desconstrutivista, que analisaremos na terceira parte deste trabalho.

O uncanny tem sua origem nos contos de E.T.A. Hoffmann (1776-1822) e Edgar Alan Poe (1809-1849), cujos temas prediletos recaiam justamente no contraste entre ambientes seguros e bem familiares e o pavor de sua invasão por presenças alheias (.alien presence.), que levariam a uma sensação de insegurança, ansiedade. O ensaio de Sigmund Freud (1856-1939) Das Unheimilich, ou The Uncanny, de 1919, por uma análise cuidadosa do conto de Hoffmann, The Sandman (1814), evidencia que o caráter do não-familiar é mais que o sentimento de não-pertencimento é, pois, a propensão do familiar de se voltar para o indivíduo e, de repente, tornar-se algo desfamiliarizado, irreal, como que num sonho. Nesta fantástica narrativa, o artifício psicológico utilizado para criar sensações de estranhamento no leitor foi deixá-lo na incerteza da natureza dos personagens, se são humanos ou autômatas, e da natureza dos acontecimentos, se são reais ou fruto da imaginação de uma criança. Esse estranhamento de que falamos lembra características da arte romântica do século XIX e possui relações com o medo da castração, da mutilação, o fenômeno do duplo . o outro igual ou a dupla personalidade . e a constante recorrência da mesma coisa . repetição de mesmas fisionomias, ou traços de caráter, ou problemas quaisquer, de mesmos crimes, eventos, ou ainda de mesmos nomes por várias gerações consecutivas (FREUD, 1919).

O uncanny, portanto, deve ser entendido como uma resposta significativa psicanalítica e estética frente o verdadeiro choque do moderno, .um trauma que, agravado pela impensada repetição numa escala maior ainda durante a Segunda Guerra Mundial, ainda não foi exorcizado do imaginário contemporâneo. (VIDLER, 1992:9). Esse trauma, ou essa inquietante estranheza, segundo Freud, é na realidade nada novo ou estranho, mas algo que é familiar e incrustado na mente humana e se tornou alienado 


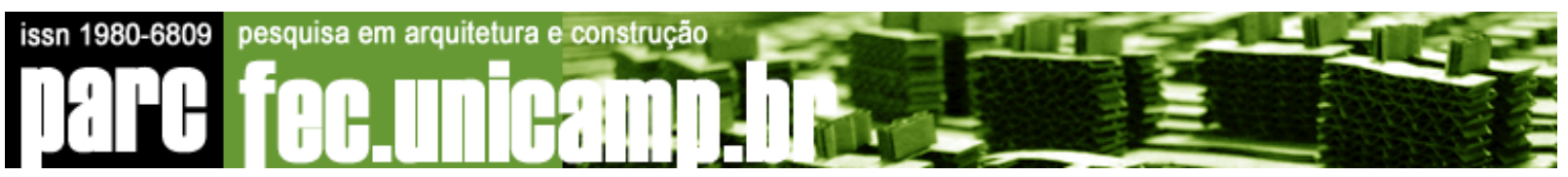

à consciência por meio do processo de repressão. O uncanny é algo que deveria ter permanecido escondido e esquecido, mas que reaparece por meio de uma determinada situação ou condição, é uma ausência que se faz presente.

No contexto da arquitetura, o estranhamente familiar é o retorno do corpo a um espaço que reprimiu a consciência de sua presença. O uncanny, entretanto, não é uma qualidade própria do espaço, nem pode ser provocado por uma conformação espacial particular; na sua dimensão estética, .ele é a representação de um estado de projeção mental que dissipa os limites entre o real e o irreal, de modo a provocar uma ambigüidade perturbante, algo entre caminhar e sonhar. (VIDLER, 1992:11). Contudo, também não se trata de um simples revivalismo de espaços comuns românticos, ou sentimentos expressos apenas em estórias de horror e fantasmas. A sua exposição teórica feita por Freud, e depois por Heidegger, o coloca no cerne das categorias que podem ser adotadas para interpretar a modernidade e especialmente suas condições espaciais, arquitetônicas e urbanas.

O que podemos chamar de .architectural uncanny. relaciona-se à capacidade da arquitetura, especialmente a residencial, de suscitar angustiantes problemas de identidade do eu, do outro, do corpo e sua ausência. Esse conceito é necessariamente ambíguo, combinando aspectos da história ficcional, sua análise psicológica e suas manifestações culturais. Se edificações ou espaços são analisados por este viés, não é por possuírem propriedades estranhamente familiares, mas por atuarem, historicamente e culturalmente, enquanto representações do estranhamento. Destarte, uma premissa importante neste estudo é a de que definitivamente não existe algo como uma .uncanny architecture., mas sim arquiteturas que, de tempos em tempos e por diversos motivos, são investidas de qualidades sublimes1.

Essa constante recorrência da mesma coisa pode ser mais bem compreendida pelo mito do eterno retorno do mesmo de Friedrich Nietzsche (1844-1900), que não só o articula a discussões estéticas, como o considera fundamental nos seus estudos, críticas e profecias sobre e para o ser humano. Arte, para o filósofo alemão, é uma organização da vida por imagens, ela imita à sua maneira a ordem do universo de modo a se configurar como uma eternização, uma vontade de superar o devir pelo seu eterno retorno. Arte é aquilo que torna a vida mais intensa, é o que nos salva da ilusão de nossas verdades; Nietzsche coloca que é preciso reconhecer o mundo da ilusão, das aparências, mesmo que seja esse o nosso único mundo real. .Tudo é ilusão, mas 


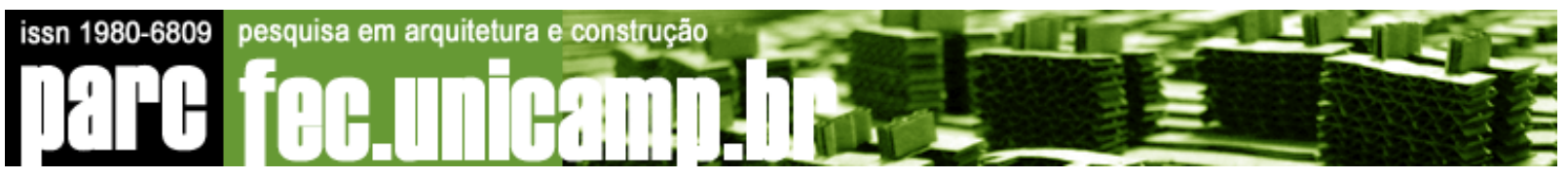

só a arte sabe que não é mais que ilusão: ela é a própria linguagem das aparências.2.

Dessa forma, há uma sobreposição e substituição entre o sonho e o inebriante, estabelecendo uma ruptura com a idéia de oposição entre belo e sublime de Winckelmann e Kant. O belo, então, seria um sonho que surge do nosso querer quando está adormecido, enquanto o sublime é o êxtase em que se funda nosso querer egoísta em que ele saboreia a alegria da libertação3.

O eterno retorno do mesmo pode ser entendido como um esforço artístico para pensar a estrutura artística do mundo. A teoria estética de Arthur Schopenhauer (1788-1860), precursor e compatriota de Nietzsche, define que a essência da arte, a Idea platônica, encontra-se no mundo como vontade de representação, onde o belo está em todas as coisas, onde a estrutura é bela, que deve ser contemplada desinteressadamente, sem a procura por explicações. A essência de qualquer coisa é aquilo que se mantém apesar do tempo, e a partir daí funda-se a idéia do eterno retorno, eliminando a oposição entre passado e futuro, atribuindo ao primeiro a marca de um porvir aberto e ao segundo a permanência e imutabilidade do passado (GRLIC, 1985:33).

Esse estranho hábito da história se repetir, de retornar a momentos inesperados ou que não se deseja reviver, juntamente com a resistência absoluta da natureza a assimilação do ser humano, suas características e atitudes, parecem confirmar a impossibilidade de se .viver confortavelmente., ou em harmonia, no mundo (VIDLER, 1992:5). Portanto, o eterno retorno do mesmo não é simplesmente uma nova dimensão do tempo, da existência dos objetos reais e de sua determinação espacial. Nesse sentido, o estranhamento parece ser uma conseqüência natural da concepção de história, da impulsão implacável do tempo que, enquanto substitui o passado em favor do presente, se mostra incerto apenas acerca do presente. Essa incerteza e ambigüidade temporal, espacial e conseqüentemente mental é inerente à nossa realidade, .toda coisa é e não é nesse lugar, todo lugar desaparece e reaparece de novo, a alma supera e nega toda limitação espacial assim como a temporalidade ordinária. (GRLIC, 1985:32).

Para Nietzsche, somente pela arte é possível despojar-se de todas as idéias e categorias criadas e impostas pela humanidade, pois o homem desnatura o mundo precisamente ao tentar compreendê-lo a partir de conceitos que ele mesmo constrói; imaginando assim a estrutura das coisas e predeterminando os fundamentos da realidade inteira e da totalidade de sua experiência (GRLIC, 1985:32). Por isso, 


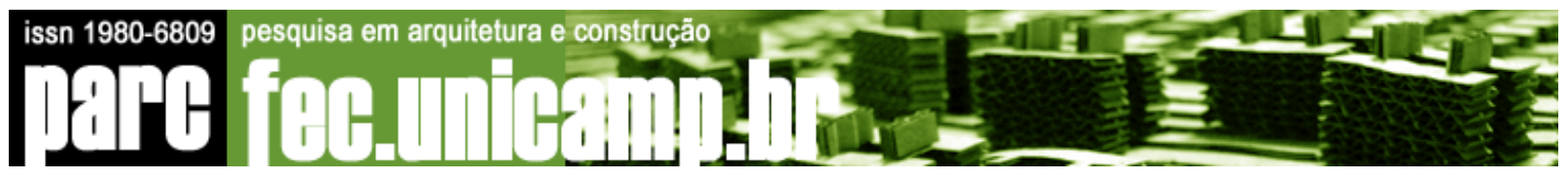

acredita que vivemos em um mundo das aparências, onde a verdade não é

exatamente a verdade, é apenas uma verdade inventada. Essa atitude consciente de tentar explicar e teorizar todos os fenômenos aliena e limita nosso ser, ou seja, o homem separa-se da realidade e não deixa de tornar-se estranho a ela com todo ato teórico desse gênero.

Somente quando o mundo e o homem juntos se fundirem numa unidade, somente quando .ontologia., .antropologia. e .estética. se puserem a falar a mesma linguagem . isto é, apenas quando o ser do ente apresentar-se também ao homem como o eterno retorno do mesmo . o homem se reencontrará a si próprio ao mesmo tempo em que se ultrapassará enquanto homem. É só então que atravessará a ponte, é só então que se poderá elevar acima das coisas e dos abismos e vencer 0 .espírito do peso., dançar a sua roda, ser artista (...) (NIETZSCHE In GRLIC, 1985:32).

Freud, ao relatar um episódio verídico seu em Genoa, evidencia uma .repetição involuntária., quando toma diversos caminhos e coincidentemente retornava sempre ao mesmo lugar de origem, que conseguia transformar uma calma cidade italiana em um lugar de .claustrofobia piranesiana.. Era como estar perdido na neblina em uma floresta de montanha, onde toda tentativa de achar alguma marca ou caminho familiar sempre o leva ao lugar de onde saiu; ou como a experiência de estar perdido num quarto escuro e estranho, procurando a porta ou o interruptor que acende a luz, mas que nunca os alcança por sempre esbarrar na mesma infinita peça de mobiliário. A sensação de .uncanniness. 4 se mostra como algo especialmente difícil de precisar. Não é nem um terror absoluto, nem uma leve ansiedade; parece ser mais fácil de descrever o uncanny pelo que não é do que por características que possam ser fundamentais para a sua constituição. Destarte, este conceito deve ser distinguido de horror e todos os sentimentos fortes relacionados a medo; ele não é exclusivamente associado com o parapsicológico . o mágico, o alucinante, o místico, o sobrenatural não necessariamente implicam em .uncanniness.; nem está presente em tudo o que parece estranho, diferente, grotesco ou fantástico; é, pois, .o diretamente oposto à caricatura e ao distorcido, que por seu exagero, recusa-se a provocar medo. (VIDLER, 1992:22). Compartilhando qualidades de todos os gêneros de medo, o uncanny revela sua não-especificidade, principalmente pela questão lingüística: pela etimologia 


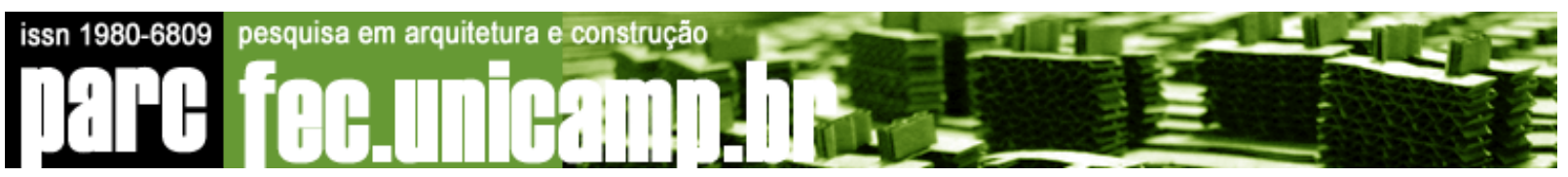

inglesa da palavra, ela significa .beyond ken., ou além do conhecimento, sendo que .canny. é .possuir conhecimento ou habilidade.. Isso dito, o psicólogo Ernest Jentsch, autor de .On the Psychology of the Uncanny. de 1906, ponto de partida para as investigações de Freud, pelas distinções semânticas de heimlich (homely) e unheimlich (unhomely), atribui o sentimento de .uncanniness. a uma forte insegurança proveniente de uma falta de orientação, uma percepção de algo novo, estranho e hostil que invade o mundo ordinário, antigo e familiar.

Todavia, Freud relutou a aceitar a definição de Jentsch, considerando-a incompleta por entender que a palavra alemã unheimlich possuía várias acepções as quais poderiam ser úteis à sua plena compreensão. Estas serviriam então para clarificar as .operações. do uncanny enquanto um princípio sistemático, assim como situar firmemente seu domínio no doméstico e no .caseiro.; e por fim permitir sua decifração nas experiências individuais como produto inconsciente de um romance familiar (VIDLER, 1992:23). Para tanto, o psicanalista deliberadamente aproximou a definição de unheimlich de seu aparente oposto, heimlich, podendo desta forma expor as perturbantes afiliações entre ambas e comprovar que uma é diretamente conseqüência da outra.

Sigmund Freud analisou o significado de heimlich em dicionários do século XIX, principalmente a partir do Wörterbuch der Deutschen Sprache (1860) de Daniel Sanders (1819-1897), e como poderíamos comprovar pelas características de seu antônimo já explicitadas, é primeiramente definido como .pertencente ao lar ou à família., .não estranho, familiar., doméstico. O termo é associado a intimidade, ao confortável, a quietude, ou ainda ao .sentimento de paz e seguridade de alguém quando dentro das quatro paredes de sua casa.. Entretanto, esse é apenas o sentido mais generalizado, ou difundido, da palavra, que também pode ser entendida como .escondido., .algo mantido fora de vista para que ninguém venha ter conhecimento dele.. De tal modo que a evolução do sentido de lar, para privado, para escondido, para secreto, e em última instância mágico, mostra-se natural se pensarmos que muito do que guardamos em nossas casas é tudo aquilo que não queremos que outros vejam; ou ainda, muito do que retemos em nossa própria mente, especialmente no inconsciente, nossos sentimentos e desejos mais íntimos, e, portanto pessoais, deve permanecer ali, fora do alcance de todos, seguro contra o mundo exterior. Similarmente, os irmãos Grimm5, incansáveis colecionadores de folclore e mitos, 


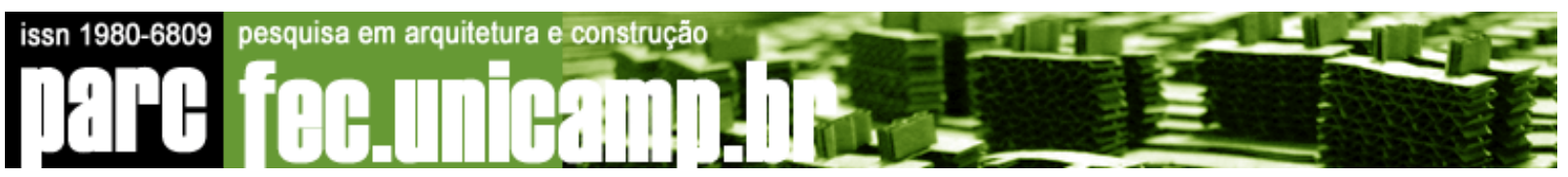

definindo heimlich em seu Deutsches Wörterbuch (1877), traçaram a idéia de .homely., ou confortável, aconchegante, a qual pertence à casa, ao lar, como um sentimento de seguridade e de estar livre do medo; mas que tende curiosamente tomar o caminho semântico de seu aparente oposto, o .unhomely.. A explanação desenvolvida sugere algo retirado da vista de estranhos, algo escondido e secreto; heimlich, no sentido de conhecimento, pode também evocar o místico, o alegórico, o oculto, ou seja, obscuro e inacessível ao conhecimento.

The notion of something hidden and dangerous...is still further developed, so that .heimlich. comes to have the meaning usually ascribed to .unheimlich.. Thus: .At times I feel like a man who walks in the night and believes in ghosts; every corner is Heimlich and full of terros for him (GRIMM Apud VIDLER, 1992:25).

A partir desse desdobramento do .homely. para o .unhomely., Freud percebeu que heimlich é uma palavra cujo sentido se desenvolve em uma direção de ambivalência, até que por fim coincide com o seu oposto, unheimlich. Por vários exemplos em Wörterbuch der Deutschen Sprache de Sanders percebe-se o senso de algo enterrado que subitamente toma forma e reaparece, de tal forma que o unheimlich parece emergir por debaixo do heimlich, como se escapasse de um esconderijo desapercebido. Destarte, a idéia da aparição de algo que deveria ter permanecido encoberto ou escondido, que o filósofo Schelling6 (1775-1854) define em Philosophie der Mythologie (1835), é o ponto fundamental para o psicanalista desenvolver a idéia de que o uncanny só poderia ser entendido pelo conceito da repressão, indo além da simples incerteza intelectual. de Jentsch.

Anthony Vidler expõe que desde o romantismo, a arquitetura possui uma ligação estreita com a idéia do estranhamente familiar, e que em um plano mais imediato, ela se tornou lugar de intermináveis explorações de situações de assombração, duplicidade, mutilações e outros horrores na literatura e na arte. A estética e a psique românticas estavam abertas a uma tal força, aparentemente morta e enterrada, que a qualquer momento poderia se reapropriar de algo seguro e livre de superstições e retornar a um estado de inquietante, como se esse sentimento não devesse ocorrer, mas sim ter permanecido esquecido nas profundezas da mente.

Uma das mais importantes representações do uncanny nas artes é exatamente a mutilação, o medo do desmembramento do corpo, ou o medo da castração. Foi 


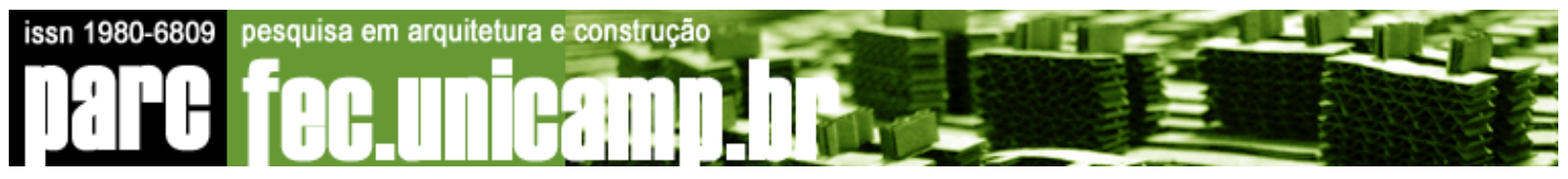

comum na estética clássica, principalmente pela escultura, a representação da perfeição do corpo como um todo pelas suas partes tomadas individualmente. A visão romântica forçou a reconciliação entre a existência material dos fragmentos e sua metafísica organicista, preferindo tomar o fragmento como ele se apresenta na natureza e cultivá-lo como objeto de meditação, contemplação. A intrínseca condição de incompletude. do fragmento coloca em cheque a relação entre homem e mundo natural, que se baseia na idéia da dominação humana sobre o meio. Quando Immanuel Kant (1724-1804) sugere a existência de algo interior, porém distinto, ao conceito de beleza, o que chamou de sublime, a incerteza do domínio do sentimento na arte se torna claro, abrindo o caminho ao desconhecido pela inversão e interposição das categorias estéticas do belo e do sublime, ou seja, para a certeza de que ignoramos muito do que nós somos e do que nosso universo é; não dominamos nada que não seja algo de nossa própria criação.

Essa questão da ambigüidade e incerteza na mente humana, intimamente ligada a necessidade do indivíduo de recriar um mundo seu, como o Éden de Adão e Eva, e a vontade de pensar, agir e sentir por si mesmo, sem que alguém ou alguma instituição Ihe diga como fazê-lo, é também presente na arquitetura, pelo espaço e pela forma, por novas maneiras de organizar o espaço, como bem coloca o arquiteto contemporâneo Lebbeus Woods7. O confronto com o estranhamente familiar, que provoca sensações (in)comuns, e a necessidade de deslocamento da arquitetura a um outro nível é o que discutiremos no item seguinte, a fim de evidenciar as repercussões do pensamento pós-estruturalista e do movimento desconstrutivista.

\section{DESLOCAMENTOS: ROMPENDO PARADIGMAS}

You can judge just how bad the 70.s were when you look at its super tense architecture.

Opinion polls and a complacent democracy live behind Biedermeierfacades.

But we don.t want to build Biedermeier. Not now and not at no other time. We are tired of seeing Palladio and other historical masks.

Because we don.t want architecture to exclude everything that is disquieting.

We want architecture to have more. Architecture that bleeds, that exhausts, that whirls and even breaks. Architecture that lights up, that stings, that rips, and under stress tears. 


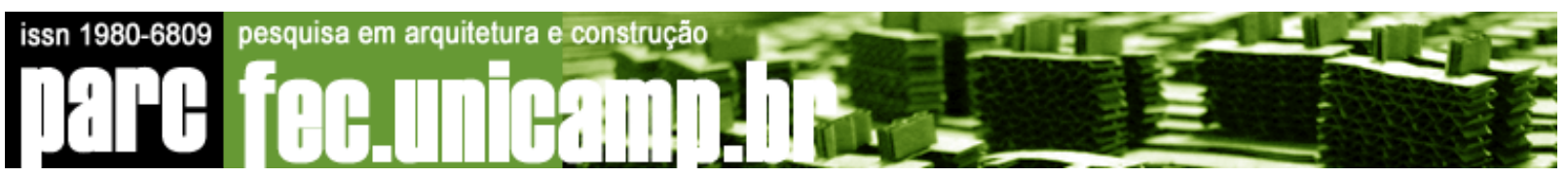

Architecture should be cavernous, firey, smooth, hard, angular, brutal, round, delicate, colorful, obscene, voluptuous, dreamy, alluring, repelling, wet, dry and throbbing. Alive or dead. Cold . than cold as a block of ice. Hot . than hot as a blazing wing.

Architecture must blaze8.

Este texto do grupo Coop Himmelb(L)au, escrito em 1980, .Architecture must blaze., evidencia claramente a vontade de substituição da maneira tradicional de pensar e fazer arquitetura. A .chama. de Wolf D. Prix e Helmut Swiczinsky se mostra como o perfeito paradigma de mutação da forma, o que os levou a idéias como a de rotação e torção de estruturas, e ainda a literal explosão dos conceitos encravados há séculos no campo arquitetônico. Aprofundaremos, nesta parte do trabalho, diversas idéias e práticas surgidas em conseqüência do discurso pós-moderno a partir da década de 1960, que privilegia a heterogeneidade e a diferença como forças libertadoras na redefinição do discurso cultural. Tais idéias surgiram principalmente pela reavaliação do conceito de arte pelo construtivismo russo, que buscava em suas obras o prazer da experiência estética pelo seu não entendimento de imediato. O propósito da arte seria facultar a sensação das coisas como são percebidas e não como são conhecidas, aproximando-se da necessidade da quebra de valores anteriormente anunciada por Nietzsche. Esse tempo é marcado pelo pensamento pós-estruturalista e pelo movimento desconstrutivista, iniciado por Jacques Derrida a partir de uma releitura das idéias heideggerianas. A desconstrução envolve conceitos como o de fragmentação, indeterminação, dissolução, dobra, e a intensa desconfiança de todos os conceitos universais ou totalizantes.

Segundo Hal Foster (Apud NESBITT, 2006:39), o paradigma pós-estruturalista levanta duas questões fundamentais pertinentes à arquitetura pós-moderna; a do estatuto do sujeito e sua linguagem e a do estatuto da história e sua representação. Ambos são construções mentais modeladas pelas representações que a sociedade possui delas. Avaliaremos, pois, o conceito de desconstrução e as idéias de dois arquitetos pioneiros no desenvolvimento de novas abordagens na arquitetura: Peter Eisenman e Bernard Tschumi.

A desconstrução analisa e questiona os pares conceituais comumente aceitos como naturais e evidentes por si mesmos, como se não tivessem sido institucionalizados em algum momento preciso, como forma e função, estrutura e ornamento, belo e feio. De 


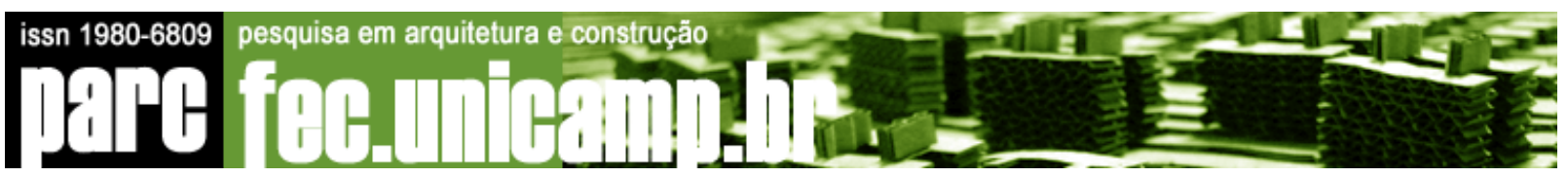

acordo com Derrida, tal teoria age nas margens, ou limites, para revelar e desmontar as oposições e os pressupostos vulneráveis que estruturam um texto; e em seguida, procura fazer um deslocamento mais geral do sistema, verificando o que a história da disciplina pode ter ocultado ou excluído, pela via da dominação e repressão, a fim de constituir sua identidade.

Eisenman, no texto .En Terror Firma: na trilha dos grotextos.9, estabelece a necessidade deste deslocamento, no sentido da substituição das antigas maneiras de conceber arquitetura. Entende que as .modalidades de ocupação do espaço requerem uma forma mais complexa do belo, uma forma que inclua o feio, ou uma racionalidade que inclua o irracional.. A experiência do deslocamento é a incerteza de conhecer parcialmente, é negar o recinto ou o lugar tradicional como meio de atingir sua interioridade (condição de .estar dentro.) e encontrar-se com o não-visto e o escavado. Segundo o autor, o objeto não precisa parecer feio ou aterrorizante para despertar a sensação de incerteza, uma vez que agora é a distância entre objeto e sujeito, a impossibilidade da posse, que provoca esta ansiedade. Baseando-se nas idéias de Kant e discussões de Vidler acerca do estranhamente familiar, coloca o grotesco na arquitetura como a manifestação do incerto no mundo físico10.

A discussão estética que travamos acerca do uncanny conseqüentemente leva ao questionamento da oposição entre forma e função. As três qualidades vitruvianas . venustas, firmitas, utilitas . que designam .aparência atraente., .estabilidade estrutural. e .acomodação espacial adequada. têm persistido na arquitetura como preceitos arquitetônicos fundamentais e inquestionáveis. Tschumi pergunta-se da validade dessas qualidades, da sua necessidade para a existência da arquitetura e desafia a própria disciplina a deslocar seus limites que a definem há tanto tempo. Sua crítica ao modernismo e ao historicismo pós-moderno evidencia a despreocupação do problema da função e do programa, uma vez que abordaram exclusivamente a exploração estilística ou formal, com base na concepção da obra arquitetônica como objeto. .A forma segue a forma, só o significado e o quadro de referência diferem. (NESBITT, 2006:183). O arquiteto sugere uma alternativa ao modo estruturalista de pensar e fazer arquitetura, entendendo esta não como obra em si, mas como uma interação do espaço com os eventos, de modo que o corpo humano esteja situado no centro das questões espaciais.

O pós-estruturalismo e a desconstrução propõem a desestabilização da idéia de um 
conjunto unificado de imagens, a idéia de certeza e de uma linguagem identificável. Da mesma forma, Bernard Tschumi cria uma teoria da disjunção enquanto uma ferramenta sistemática para a produção arquitetônica, implicando que nenhuma das partes do projeto pode transformar-se em uma síntese ou totalidade auto-suficiente, mas que cada parte leva à outra e toda construção é desestabilizada pelos vestígios de uma outra construção. Apóia-se também na rejeição da oposição tradicional entre uso e forma em favor da sobreposição ou justaposição de dois termos; e na ênfase no método da dissociação, superposição, combinação, que .desencadeiam forças dinâmicas capazes de se expandir para todo o sistema arquitetônico, explodindo os seus limites e, ao mesmo tempo, sugerindo uma nova definição. (TSCHUMI, 1998:212).

Jacques Derrida explicita que a desconstrução não se trata simplesmente da técnica de um arquiteto de desconstruir aquilo que foi construído, mas de uma investigação que se refere diretamente à própria técnica, .à autoridade da metáfora arquitetônica e que, portanto, institui sua própria retórica arquitetônica. 11. O filósofo percebe que a heterogeneidade inerente ao discurso pós-moderno permite a colagem e montagem de textos, estimulando a produção de uma significação que não deve se mostrar unívoca nem estável. Por conseguinte, é possível procurar dentro de um texto por outro, dissolver um texto em outro ou embutir um texto em outro. Pelo questionamento de todas as ilusões de sistemas fixos de representação, o autor elabora duas formas de leitura: do fragmento percebido com relação ao seu texto de origem; e do fragmento incorporado a um novo todo, a uma totalidade distinta (HARVEY, 2003:55). O deslocamento a que pretende Peter Eisenman baseia-se na constante reinvenção da arquitetura, o que o levou a considerá-la como uma categoria textual. Isso implica a deslocalização da interpretação tradicional de seus elementos de modo que suas figuras possam ser lidas retoricamente, e não estética ou metaforicamente. Uma figura retórica é aquela que tem reduzido o seu tradicional conteúdo elementar, estrutural, estético; e para a sua construção é necessária a introdução de uma ausência no ser da arquitetura, uma ausência em sua presença. $O$ arquiteto cria estratégias para tanto, como o palimpsesto, o enxerto e a idéia de traço ou rastro, uma vez que a ausência tem sido classicamente reprimida pela presença. Vista retoricamente, a arquitetura é composta com um outro contraponto gramatical, que não o de elementos estéticos e estruturais, que propõe uma leitura alternativa de sítio e objeto: passa a ser 


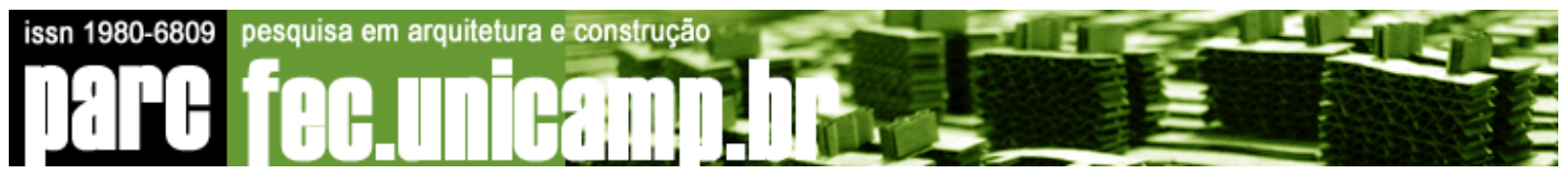

intrinsecamente contextual, porque o sítio é tratado como um palimpsesto12 cheio de registros. O contextualismo tradicional, representacional e analítico, trata o lugar como uma presença física, enquanto o processo utilizado pelo referido autor, por possuir um caráter analógico, dissolve e inebria as implicações do sítio em relação a seus significados culturalmente determinados pela sobreposição de conteúdos antigos a fim de construir um novo.

A textualidade sugere a presença de uma ausência, um rastro, de modo a deslocalizar a essência conceitual de suas típicas estruturas prévias . hierarquia, espaço, tempo, lugar, etc. . retirando o significado .original. desses elementos. .Esse texto reprimido é uma ficção que reconhece sua condição fictícia. Desse modo, começa a aceitar a qualidade ficcional da realidade e a qualidade real da ficção. (EISENMAN, 2006:199). Eisenman, em 1982, não mais estava interessado em filosofia, mas sim em ficções e poéticas; e neste estágio surgiram suas teorias e seus projetos sobre as cidades fictícias e o fim do Clássico. A concepção das .Cities of Artificial Excavation., utilizada no projeto de Cannaregio em Veneza, possui três idéias principais: a relação da arquitetura com a cidade; a eliminação do valor agregado a processos de projeto racionalizados; e a criação fictícia, por meio de textos e desenhos, de traços associados ao lugar (BEDARD, 1994:13). Percebemos que as noções de traço e palimpsesto, não por acaso, mas por se tratarem de métodos de provocar a desestabilização, relacionam-se diretamente com as investigações do arquiteto John Hejduk acerca de associações pisicológicas que resultam em uma forma de arquitetura mais questionadora:

1 That architectural tracings are apparitions, outlines, figments.

They are not diagrams but ghosts.

2 Tracings are similar to X-rays, they penetrate internally.

3 Erasures imply former existences.

4 Drawings are like the hands of the blind touching the surfaces of the face in order to understand a sense of volume, depth and penetration.

5 The lead of an architect.s pencil disappears (drawn away) metamorphoses.

To take a site: present tracings, outlines, figments, apparitions, X-rays of thoughts. Meditations on the sense of erasures. To fabricate a 


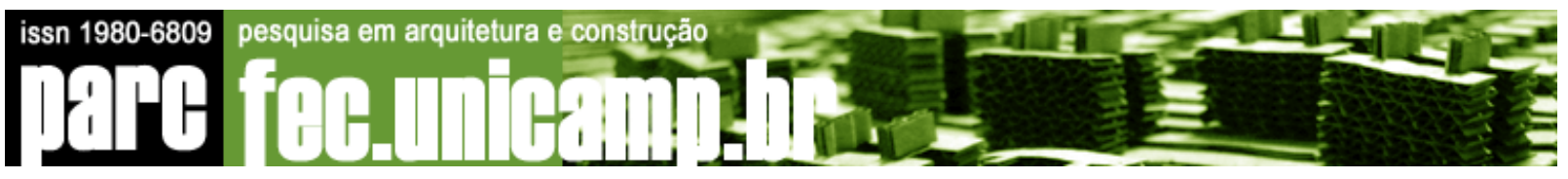

construction of time.

To draw out by compacting in. To flood (liquid densification) the placesite

with missing letters and disappeared signatures. To gelatinize

forgetfulness (HEJDUK In JENCKS, 1997:285).

Uma de suas principais estratégias de projetação é o scaling, derivado das teorias do Caos e dos Fractais, que consiste em infinitas reduções, ampliações e repetições de irregularidades e anomalias de figuras retiradas de mapas históricos . como contorno de rios, plantas de edificações, formato de territórios, etc . de forma a desestabilizar a narrativa. Da mesma forma faz uso de superposições e rotações entre si e elementos novos, acoplados ao contexto, sem que nunca se atinja uma síntese final pela possibilidade de futuras .escavações.. Esses enxertos (grafts) baseiam-se na introdução de corpos estranhos que provocam uma série de transformações na estrutura interna do hospedeiro, e caracteriza-se por um processo impossível de ser controlado e manipulado, uma vez que o ato é inerente à estrutura e acontece nela e por ela mesma (RENNÓ, 2006:40). Isso porque tais implantes-fragmento mostram-se como lugares artificiais e arbitrários, que liberam o arquiteto dos automatismos de um sistema de valores não-arbitrários, ou seja, o clássico: é a desconstrução do poder do autor de impor significados ou de oferecer uma narrativa contínua, como aponta Jacques Derrida. É um espaço aberto a possibilidades, que enfatiza, não o produto final, mas processo de formação arquitetural de um espaço, pela sua eterna reinvenção. O procedimento do scaling, como Eisenman o define, inclui três princípios interdependentes, que juntos constituem um modelo operacional para sua arquitetura .não-clássica.: recursivity, a recorrência de formas matemáticas por subdivisões, destina-se a destruir a primazia do que constitui a natureza do original; self-similarity, a proliferação de formas .não-idênticas., tem o intuito de eliminar a escala humana como ponto de referência; e discontinuity, a fragmentação de figuras geométricas, tenta enfraquecer o poder da forma arquetípicas puras (BÉDARD, 1994:15). Em Visions Unfolding: Architecture in the Age of Eletronic Media, de 1992, o arquiteto introduz 0 conceito, emprestado de Gilles Deleuze, de dobra com a intenção de atingir o deslocamento da concepção tradicional de espaço. $O$ espaço dobrado seria, pois, uma alternativa ao espaço cartesiano normativo da grelha; propõe inscrevê-lo de modo a dotá-lo da possibilidade de retornar o olhar até o sujeito, a partir daquilo que não pode ser apreendido pela razão, mas que encontra-se escondido e se revela no momento 


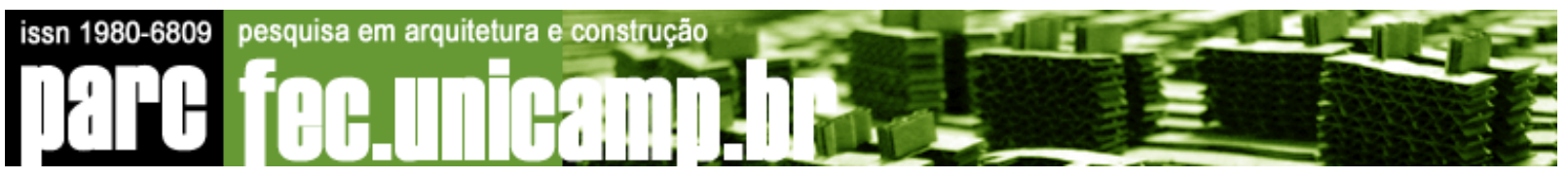

da experiência. É aberta ao sujeito a chance de enxergar uma alteridade, reprimida pela visão, que mostra-se oculta na presença (RENNÓ, 2006:70).

A evolução de seus projetos e teorias aponta para a crítica à repressão clássica da instabilidade na arquitetura causada pelos indiscutíveis pressupostos de verdade, beleza e harmonia, que na verdade estabelecem-na como uma convenção, algo totalmente não-natural 13. O deslocamento necessário para ultrapassar os limites impostos estaria na eliminação de três ficções por séculos mantidas intactas: a ficção da representação, que desde o renascimento atua na simulação de um sentido para a arquitetura e na busca de um significado existencial para cada espaço criado; a ficção da razão, em que a busca das origens da arquitetura é a manifestação inicial da aspiração por um ponto de partida racional para a concepção da forma, ou seja, baseia-se na simulação da verdade; e a ficção da história, cuja simulação do intemporal e o entendimento da história com um eterno ciclo temporal levou à idéia do Zeitgeist, ou o espírito de época, ao pressupor que o homem deveria estar sempre em harmonia com seu tempo . a tão almejada intemporalidade do presente (EISENMAN, 2006:233-252). Peter Eisenman evidencia em suas análises críticas que apesar dos modernos clamarem completa independência da arquitetura do passado, ainda mantinham a antiga fascinação com o ideal clássico da atemporalidade, do significado e da verdade, e assim como Tschumi assinala a emergência por discursos e valores arquitetônicos alternativos.

As contradições internas da arquitetura sempre estiveram lá: elas são parte de sua natureza: a arquitetura é entendida a partir de dois termos mutuamente exclusivos . espaço e seu uso, ou, num sentido mais teórico, a concepção do espaço e a experiência do espaço. A interação entre espaço e atividades aparece, para mim [Bernard Tschumi], como um caminho possível de ultrapassar os obstáculos que acompanham as ansiedades relacionadas às funções social e política da arquitetura (TSCHUMI, 1998:16).

Enquanto Eisenman discute a questão da dualidade da forma e seu uso, Tschumi questiona tanto a questão da função em arquitetura, como a função da arquitetura. As concepções de espaço e lugar possuem poucas relações com a dos fenomenólogos, Christian Norberg-Schulz, que promovem o conceito de lugar com intuito de neutralizar as deficiências do espaço modernista. O problema aí não é o espaço exatamente, mas 


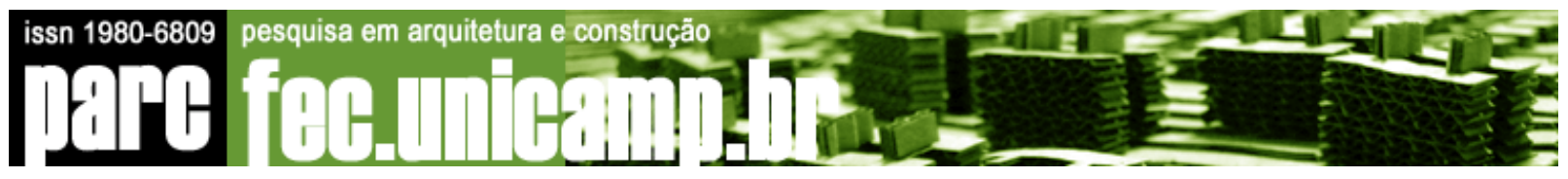

a sua programação em termos de função e não como evento (NESBITT, 2006:178).

A noção estática dos conceitos de forma e função precisam ser substituídas pela atenção às ações que ocorrem dentro e ao redor dos edifícios, ao movimento dos corpos, às atividades, às aspirações, e em última instância à própria dimensão sóciopol ítica da arquitetura.

Destarte, arquitetura é para o arquiteto francês tanto algo ligado à mente quanto ao corpo, é o .evento empírico que se concentra nos sentidos, na experiência do espaço. (TSCHUMI, 1998:83). Assim, as considerações sobre intertextualidade, múltiplas leituras e codificações deveriam se associar à noção de programa, e não apenas à de forma; os arquitetos deveriam integrar os mesmos dispositivos de distorção, repetição e justaposição às atividades que acontecem naquela forma. Em Event-Cities (Praxis), de 1994, estabelece que não há arquitetura sem ação ou destituída de programa, e a sua importância reside na habilidade em acelerar a transformação da sociedade pelo cuidadoso arranjo de espaços e eventos.

Michel Foucalt conceitua evento como algo que consiste no colapso, no questionamento e na problematização das direções que foram determinadas para algo, ocasionando, assim a possibilidade de novas direções (RENNÓ, 2006:106). A partir dessa consideração, Tschumi busca em seus projetos a heterotropia: ricas colisões de programas e espaços, nas quais os termos se misturam, combinam e influenciam uns aos outros na produção de uma nova realidade arquitetônica. $A$ grande diferença entre arquitetura e as demais artes visuais é justamente a experiência dos corpos se movendo no espaço, com o engajamento de todos os seus sentidos.

A arquitetura do prazer está onde o conceito e a experiência do espaço coincidem abruptamente, onde os fragmentos da arquitetura colidem e se fundem em deleite, onde a cultura da arquitetura é eternamente desconstruída e as regras são transgredidas (TSCHUMI, 2006:581).

Entendemos, portanto, que o prazer máximo da arquitetura está nos aspectos mais proibidos do ato arquitetônico, e o ponto de partida é justamente a distorção: o deslocamento do universo que cerca o arquiteto. $O$ autor adverte que não se trata de destruição, mas do excesso, das diferenças, das sobras. Exceder os dogmas funcionalistas, a idéia linear de história, a os sistemas semióticos, ou uma produção 


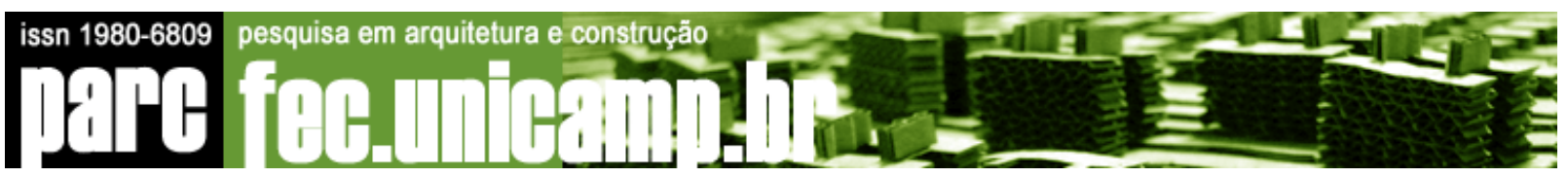

atual baseada em condições, ou restrições, sociais e econômicas passadas não se mostra necessariamente como uma vontade vanguardista de subversão; mas sim de .preservação da capacidade erótica da arquitetura. por meio da ruptura do modo como a maioria das sociedades conservadoras espera dela (TSCHUMI, 2006:581). Trata-se de causar desconforto e desequilíbrio às expectativas, de questionar os pressupostos acadêmicos e populares, incomodar os gostos adquiridos e as memórias estimadas. Tschumi aponta que esta arquitetura é perversa porque sua verdadeira significação está fora da utilidade ou finalidade, e nem sequer se propõe a dar prazer; e pode ser que a necessidade da arquitetura esteja exatamente em sua desnecessidade.

(...) o interesse da arquitetura não se deve aos seus fragmentos, ou ao que representam ou não representam. Tampouco consiste em exteriorizar, por meio de uma forma qualquer, os desejos inconscientes da sociedade ou de seus arquitetos. E também não é mera representação desses desejos por intermédio de alguma imagem arquitetônica fantástica. Na verdade, só pode agir como um recipiente em que seus desejos, meus desejos, podem ser refletidos. Assim, uma obra de arquitetura não é arquitetural porque seduz, ou porque preenche dada função utilitária, mas porque põe em ação as operações da sedução e do inconsciente (TSCHUMI, 2006:583).

$\mathrm{Na}$ arquitetura praticada por Tschumi, e mais dramaticamente pelo grupo Coop Himmelb(L)au, a consideração do inexistente, de uma ausência que sempre está à espreita pela oportunidade de se tornar presente, estabelece a questão do corpo como o ponto fundamental na arquitetura contemporânea. O prazer do espaço é algo impossível de ser descrito em palavras, anuncia o autor francês, é como se fosse uma forma de experiência pelas inebriantes diferenças entre as superfícies, pelas simetrias e assimetrias que acentuam as propriedades espaciais do corpo. Levado ao limite, o prazer do espaço tangencia a poética do inconsciente, para o limiar da loucura, pelo sentimento da presença de uma ausência como resposta a projeções espaciais refletidas de empatia corporal, que operam quase que visceralmente no corpo. VIDLER (1992:78) aponta que a confusão entre como o espaço é percebido e como ele realmente é reflete o auto-desmembramento do sujeito, no sentido de evidenciar sua própria confusão interna e desagregação, inerente ao mundo pós-moderno. A degradação do corpo é certamente uma autocrítica de um modernismo que impõe 
um papel propedêutico e quase científico à arquitetura. $O$ corpo em desintegração reflete a imagem da noção do progresso humanista em dissolução. A agressividade espacial presente no desconstrutivismo opera principalmente no âmbito da evocação do estranho pelo aparente retorno de alguma coisa que parece ter sido perdida que agora se mostra presente. Neste contexto, o deslocamento pós-estruturalista de Eisenman, Tschumi, Coop Himmelb(L)au, Lebbeus Woods, Daniel Libeskind, entre outros, situa-se, pois, no retorno do corpo à arquitetura que reprimiu sua presença consciente referente ao senso de inquietude, desde Vitruvius com o estabelecimento da harmonia pelos preceitos de venustas, firmitas, utilitas.

\section{Referências}

BÉDARD, Jean-François. Cities of artificial excavation : the work of Peter Eisenman, 1978-1988. New York: 1994. 236p.

CEJKA, Jan; STADTLANDER, Karin. Tendencias de la arquitectura contemporánea. 3. ed. México: Gustavo Gili, 1999. 136p.

DERRIDA, Jacques. Uma arquitetura onde o desejo pode morar. Entrevista de Jacques Derrida a Eva Meyer. In: NESBITT, Kate (org). Uma nova agenda para a arquitetura: uma ontologia teórica (1965-1995). Tradução de Vera Pereira.

São Paulo: Cosac Naify, 2006. p.166-172.

EISENMAN, Peter. The city of Artificial Excavation. In: BÉDARD, Jean-François. Cities of artificial excavation : the work of Peter Eisenman, 1978-1988. New York:

1994. p.73-80.

. O pós-funcionalismo. In: NESBITT, Kate (org). Uma nova agenda para a arquitetura: uma ontologia teórica (1965-1995). Tradução de Vera Pereira. São Paulo: Cosac Naify, 2006. p.97-103.

A arquitetura e o problema da figura retórica. In: NESBITT, Kate (org). Uma nova agenda para a arquitetura: uma ontologia teórica (1965-1995). Tradução de Vera Pereira. São Paulo: Cosac Naify, 2006. p.193-199.

O fim do clássico: o fim do começo, o fim do fim. In: NESBITT, Kate (org). Uma nova agenda para a arquitetura: uma ontologia teórica (1965-1995). Tradução de Vera Pereira. São Paulo: Cosac Naify, 2006. p.233-252.

Visões que se desdobram: a arquitetura na era da mídia eletrônica. In:

NESBITT, Kate (org). Uma nova agenda para a arquitetura: uma ontologia teórica (1965-1995). Tradução de Vera Pereira. São Paulo: Cosac Naify, 2006. p.600-607.

. En Terror Firma: na trilha dos grotextos. In: NESBITT, Kate (org). Uma nova agenda para a arquitetura: uma ontologia teórica (1965-1995). Tradução de Vera Pereira. São Paulo: Cosac Naify, 2006. p.612-617.

FREUD, Sigmund. The Uncanny. s/ed. 1925.

GRLIC, Danko. Nietzsche e o eterno retorno do mesmo ou o retorno da essência artística na arte. In: MARTON, Scarlett. Nietzsche hoje?: Coloquio de Cerisy.

São Paulo: Brasiliense, 1985. p.31-43.

HALE, Jonathan A. Building Ideas: An Introduction to Architectural Theory. Chichester: Wiley, 2000.

HARVEY, David. Condição pós-moderna: uma pesquisa sobre as origens da mudança 


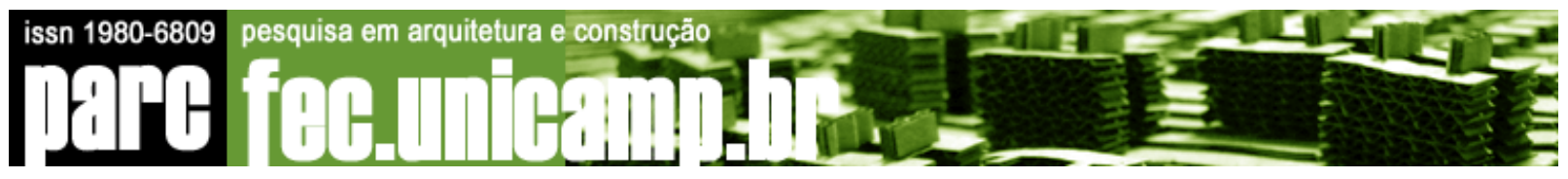

cultural. 12a ed. São Paulo: Loyola, 2003. 349p.

HOFFMANN, E.T.A. The Sandman. 1814

JENCKS, Charles. Deconstruction: The Pleasures of Absence. In: PAPADAKIS,

Andreas; COOKE, Catherine; BENJAMIN, Andrew. Deconstruction : omnibus

volume. London: Academy Editions, 1989. p.119-131.

JENCKS, Charles. Movimentos Modernos em Arquitetura. Tradução de José Marcos

de Lima. São Paulo: Martins Fontes, 1985.

JENCKS, Charles (ed); KROPF, Karl (ed). Theories and Manifestoes of Contemporary

Architecture. Chichester, West Sussex: Academy Editions, 1997. 312p.

JUNG, Carl G. O Homem e seus Símbolos. 10ª ed. Rio de Janeiro: Nova Fronteira, 1964.

MARTON, Scarlett. Nietzsche: das forças cosmicas aos valores humanos. 2. ed. Belo

Horizonte: Ed. UFMG, 2000. 290 p

MONTANER, Josep Maria. Después del Movimiento Moderno: arquitectura de la

segunda mitad del siglo XX. 4aㅡ ed. Barcelona: Editorial Gustavo Gili, 1999.

NESBITT, Kate (org). Uma nova agenda para a arquitetura: uma ontologia teórica

(1965-1995). Tradução de Vera Pereira. São Paulo: Cosac Naify, 2006. 659p.

NOEVER, Peter. Architecture in Transition: Between Deconstruction and New

Modernism. Munich: Prestel, 1991.

NORBERG-SCHULZ, Christian. Genius Loci: towards a phenomenology of

architecture. New York: 1979. 213 p.

PAPADAKIS, Andreas; COOKE, Catherine; BENJAMIN, Andrew. Deconstruction :

omnibus volume. London: Academy Editions, 1989. 264p.

POE, Edgar Allan. Assassinatos na rua Morgue e outras histórias. Porto Alegre: L\&PM, 2002. 156p.

RENNÓ, Silvia de Alencar. Existe uma experiência estética do usuário nos discursos da arquitetura contemporânea? Aproximações a partir das categorias críticas

de Peter Eisenman e Bernard Tschumi. Dissertação de Mestrado em

Arquitetura e Urbanismo da Escola de Arquitetura da Universidade Federal de

Minas Gerais. 2006.

TSCHUMI, Bernard. Event-Cities (Praxis). Cambridge/London: The MIT Press, 1994.

Architecture and disjunction. Cambridge: The MIT Press, 1996. 268 p.

Arquitetura e Limites I. In: NESBITT, Kate (org). Uma nova agenda para a

arquitetura: uma ontologia teórica (1965-1995). Tradução de Vera Pereira. São

Paulo: Cosac Naify, 2006. p.173-177.

Arquitetura e Limites II. In: NESBITT, Kate (org). Uma nova agenda para a

arquitetura: uma ontologia teórica (1965-1995). Tradução de Vera Pereira. São

Paulo: Cosac Naify, 2006. p.179-182.

Arquitetura e Limites III. In: NESBITT, Kate (org). Uma nova agenda para a

arquitetura: uma ontologia teórica (1965-1995). Tradução de Vera Pereira. São

Paulo: Cosac Naify, 2006. p.184-188.

Arquitetura e Limites III. In: NESBITT, Kate (org). Uma nova agenda para a

arquitetura: uma ontologia teórica (1965-1995). Tradução de Vera Pereira. São

Paulo: Cosac Naify, 2006. p.184-188. Introdução: notas para uma teoria da disjunção arquitetônica. In: NESBITT,

Kate (org). Uma nova agenda para a arquitetura: uma ontologia teórica (1965-

1995). Tradução de Vera Pereira. São Paulo: Cosac Naify, 2006. p.184-188.

O prazer da arquitetura. In: NESBITT, Kate (org). Uma nova agenda para a

arquitetura: uma ontologia teórica (1965-1995). Tradução de Vera Pereira. São

Paulo: Cosac Naify, 2006. p.574-584.

VENTURI, Robert. Complexidade e Contradição em Arquitetura. São Paulo: Martins

Fontes, 1995.

VIDLER, Anthony. The architectural uncanny: essays in the modern unhomely.

Cambridge: The MIT Press, 1992. 257p. 
Uma teoria sobre o estranhamente familiar. In: NESBITT, Kate (org). Uma nova agenda para a arquitetura: uma ontologia teórica (1965-1995). Tradução de Vera Pereira. São Paulo: Cosac Naify, 2006. p.619-622.

WIGLEY, Mark. Deconstructivist Architecture. In: PAPADAKIS, Andreas; COOKE, Catherine; BENJAMIN, Andrew. Deconstruction : omnibus volume. London:

Academy Editions, 1989. p.132-134.

\section{Notas}

1 Como o estranhamente familiar não pode ser provocado ou planejado deliberadamente, a Teoria de Vidler não pode ser prescritiva, o que a aproxima do conceito de grotesco de Peter Eisenman, que será tratado no terceiro capítulo desta monografia.

2 Notas de aula da Professora Doutora Celina Borges Lemos, tutora do PET Arquitetura UFMG, sobre o pensamento estético-filosófico no século XIX.

3 lbidem.

4 Mesmo não achando o significado exato da palavra .uncanniness. em diversos dicionários de língua inglesa, podemos defini-lo gramaticamente como a substantivação do adjetivo .uncanny.. No caso, o termo designaria o estado de .inquietante estranhamento. por algo que se mostra familiar e estranho ao mesmo tempo.

5 Jakob Ludwig Carl Grimm (1785-1863) e Wilhelm Karl Grimm (1786-1859). Seu dicionário etimológico, um dos mais importantes na língua alemã, foi iniciado em 1838 e quando o projeto foi finalizado em 1861, ele já continha 32 volumes e mais de 350.000 palavras. 6 Friedrich Wilhelm Joseph von Schelling foi um dos representantes do Idealismo alemão, assim como Fichte e Hegel.

7 Ver WOODS, Lebbeus In NOEVER, Peter (1991:133). Palestra, transformada em texto, a convite do Austrian Museum of Applied Arts, em Viena.

8.Architecture must blaze", 1980. Ver NOEVER, Peter. Architecture in Trasition: Between Deconstruction and New Modernism. Munich: Prestel, 1991. p. 31.

9 Ver NESBITT, 2006:615; e PAPADAKIS, 1989:152.

10 Segundo Eisenman, a categoria do sublime corresponderia ao etéreo, enquanto o grotesco é referenciado como substância concreta. 11 Ver entrevista de Jacques Derrida a Eva Meyer: Uma arquitetura onde o desejo pode morar, em NESBITT, 2006:168.

12 Palimpsesto é uma espécie de papiro ou pergaminho cujo texto foi raspado para dar lugar a outro.

13 Ver Blue Line Text de Eisenman em BEDARD, 1994:150-151. 